\title{
BMJ Open Association between systolic blood pressure trajectories and hypertension risk at late adolescence: results from 10- year longitudinal follow-up in Chinese boys
}

Xijie Wang (D) , ${ }^{1}$ Bin Dong, ${ }^{1}$ Sizhe Huang, ${ }^{2}$ Zhaogeng Yang (D) , Jun Ma (D) , Jie $\mathrm{Hu}^{3}$

To cite: Wang $X$, Dong $B$, Huang $S$, et al. Association between systolic blood pressure trajectories and hypertension risk at late adolescence: results from 10-year longitudinal follow-up in Chinese boys. BMJ Open 2021;11:e042594. doi:10.1136/ bmjopen-2020-042594

- Prepublication history and additonal supplemental material for this paper is available online. To view these files, please visit the journal online (http://dx.doi. org/10.1136/bmjopen-2020042594).

Received 13 July 2020 Revised 16 March 2021 Accepted 22 March 2021

\section{Check for updates}

(c) Author(s) (or their employer(s)) 2021. Re-use permitted under CC BY-NC. No commercial re-use. See rights and permissions. Published by BMJ.

${ }^{1}$ Institute of Child and Adolescent Health \& School of Public Health, Peking University, Beijing, China

${ }^{2}$ Zhongshan Health Care Centers for Primary and Secondary School, Zhongshan, Guangdong, China

${ }^{3}$ Menzies Health Institute Queensland, Griffith University, Nathan, Queensland, Australia

Correspondence to Professor Jun Ma; majunt@bjmu.edu.cn and Dr Bin Dong;

bindong@bjmu.edu.cn

\section{ABSTRACT}

Objective To identify various systolic blood pressure (SBP) trajectories in Chinese boys between 7 and 18 years of age, and to explore their high blood pressure (HBP) risk in their late adolescence years.

Design and settings A population-based cohort study in Guangdong, China.

Participants 4541 normal tensive boys who started primary school in 2005 in Zhongshan, Guangdong were included.

Outcomes Blood pressure and relevant measurements were obtained by annual physical examinations between 2005 and 2016. HBP was defined by SBP or diastolic blood pressure $\geq 95$ th percentile for children under 13 , and $\mathrm{BP} \geq 130 / 80 \mathrm{~mm} \mathrm{Hg}$ for children $\geq 13$ years old. Logit regression for panel data and log-binomial regression model was used to estimate the risk of HBP among SBP trajectory groups.

Results Four distinct SBP trajectory groups via groupbased trajectory modelling: low stable $(13.0 \%)$, low rising $(42.4 \%)$, rising (37.4\%) and high rising (7.3\%). The overall incidence rates of HBP during the follow-up ranged from 40.24 (95\% Cl 36.68 to 44.19$) / 1000$ person-years in the low stable group to 97.08 (95\% Cl 94.93 to 99.27$) / 1000$ person-years in the high rising group. Compared with children with low stable SBP, those of other SBP trajectories suffered $3.05(95 \% \mathrm{Cl} 2.64$ to 3.46$)$ to 4.64 $(95 \% \mathrm{Cl} 4.18$ to 5.09$)$ times of higher risk of HBP in their late adolescence, regardless of their age, body mass index and BP level at baseline.

Conclusions Subgroups of SBP trajectories existed in Chinese boys, and are related to hypertension risk at late adolescence. Regular physical examinations could help identify those with higher risks at the beginning of pubertal growth.

\section{INTRODUCTION}

Hypertension is a leading cause of mortality worldwide, and accounts for half of the cardiovascular disease (CVD) events in adults. ${ }^{12}$ Although the majority of paediatric population would not be diagnosed as
Strengths and limitations of this study

- One of the first studies mapping systolic blood pressure trajectories in Asian children with more than 8 years follow-up.

- The study presented that how regular physical examination data could be used for analyses and be used to help improve the efficiency of school-based health programme.

- Only boys were included in the present study. The conclusion needs to be verified in girls.

- The participants were tracked to their late adolescence in the present study. Studies in middle and old age population are warranted to provide further evidence to the relationship between blood pressure trajectories and cardiovascular health.

hypertension, ${ }^{3}$ high-risk population could be asymptomatic, with their blood pressure (BP) gradually progressed to hypertension. ${ }^{4}$ Elevated BP has negative impact on children's cardiovascular system, and the damage could last through lifetime. ${ }^{5}$

In this context, it is suggested that approaches that identifying those at greatest risk of developing hypertension in early life to be adopted to promote effective risk reduction, and to implement age-appropriate prevention and intervention strategies in paediatric population. ${ }^{6}$ Adolescents are at a critical transition from children to adults, whose BP levels could be affected by many developmental factors including intrauterine, postnatal, familial, psychosocial and individual influences, ${ }^{7-10}$ making it difficult to recognise high-risk population before they have hypertensive symptoms. BP trajectory, however, provides a rather intuitive view on BP change, and may help to identify children with elevated hypertension risk . 
Recent studies have shown that BP trajectory, especially systolic BP (SBP) trajectory, is one of the most important predictors of future cardiovascular morbidity and mortality. ${ }^{6} 1112$ Patterns of BP trajectories in white and black children have been reported with several representative cohorts like the Dunedin Multidisciplinary Health and Development Study from New Zealand, ${ }^{6}$ Birth to Twenty from South Africa ${ }^{9}$ or the Georgia Stress and Heart (GSH) study from the United States. ${ }^{13}$ However, this information is limited on Asian children. As the Asian society is experiencing rapid growth in hypertension prevalence due to growing ageing populations and the subsquent incidence of hypertension-related haemorrhagic stroke is high, ${ }^{14} \mathrm{BP}$ trajectories for Asian children may provide important information for developing region-specific strategies on disease prevention.

In this study, using physical examination data from primary and middle schools of Zhongshan city in Guangzhou province between 2005 and 2016, we aimed to identify latent groups of boys sharing SBP developmental trajectories from 7 to 18 years, and to describe the association between SBP trajectory groups and hypertension risk in their late adolescence.

\section{MATERIALS AND METHODS \\ Data source}

Datasets collected from the Zhongshan school physical examinations between 2005 and 2016 were used in this study. All students from municipal primary and secondary schools in Zhongshan, Guangdong, were required to have an annual physical examination. All assessments were conducted by qualified medical physician from medical establishments, and the results of each examination were recorded immediately into computer system by school nurses after the examination. Students who started grade one between 2005 and 2006 were included in this study, and were assessed annually to their 16-18 years old. Details of the study recruitment was illustrated in online supplemental figure 1 . The use of the present dataset has been approved by Zhongshan Health Care Centers for Primary and Secondary School. All personal information which could lead to identify the specific child was removed from the data before use.

\section{Patient and public involvement}

No patient was involved in the present study.

\section{Measurements}

Height was measured using the portable stadiometer (model TZG, China) to the nearest $0.1 \mathrm{~cm}$, with students standing straight barefoot. Weight was measured with lever type weight scale (model RGT-140, China) to the nearest $0.1 \mathrm{~kg}$ with students wearing undergarments. Body mass index (BMI) was calculated as weight $(\mathrm{kg}) /$ height $^{2}\left(\mathrm{~m}^{2}\right) .^{15}$

BP was measured by auscultatory method with mercury sphygmomanometers (model XJ11D, China), stethoscopes (model TZ-1, China), and appropriate cuffs. Participants were asked to sit quietly for at least $5 \mathrm{~min}$ prior to the first reading. SBP was determined by onset of the first Korotkoff sound and diastolic BP (DBP) was determined by the fifth Korotkoff sound. BP was measured twice with 5 min gap between the two measurements from the right arm, and the average of SBP and DBP values were recorded. This process was repeated if the difference between the two measurements was $\geq 10 \mathrm{~mm} \mathrm{Hg}$ (either for SBP or DBP).

High BP (HBP) during the follow-up was defined if the single-occasion measurement of $\mathrm{BP} \geq 95$ th percentile for children under 13 , and $\mathrm{BP} \geq 130 / 80 \mathrm{~mm} \mathrm{Hg}$ for children $\geq 13$ years old. ${ }^{5} \mathrm{HBP}$ at endpoint was defined with the BP outcomes of the last two measurements for each participant (when both measurements were defined as HBP).

\section{Statistical analysis}

The present study included a total of 38518 measurements from 4541 boys who were normal tensive at first measurement (baseline). Group-based trajectory modelling was performed to identify different trajectory groups of SBP. ${ }^{16}$ A censored normal model for continuous variables was conducted by sex with the following steps. ${ }^{17}$ First, a one-trajectory model was conducted to determine whether shapes of SBP trajectories were linear, quadratic or cubic according to the Bayesian information criteria (BIC). Second, the number of trajectory groups in the model was increased by one and these two steps were repeated until the best fit model was found. Model selection was mainly based on the absolute value of BIC. However, it was modified by (1) BIC decreased at least 20 , (2) high mean posterior probability $(>0.7)$ and (3) the odds of correct classification based on the posterior probabilities of group membership $>5$ for each group. ${ }^{18} 19$ Since the best model for boys and girls were different, only data of boys were analysed in the present study, and the best-fit model was cubic trajectories of four groups. The model fitting outcomes were displayed in online supplemental table 1.

Incidence rate and 95\% CIs of HBP during the follow-up were calculated for each age. Logit regression for panel data was used to estimate HBP risk among four trajectory groups during the follow-up, while log-binomial regression model was used to evaluate the hypertension risk of the four groups at endpoint. Tendency for differences across trajectory groups was conducted with a linear trend test. Children's age, living area (urban or rural), SBP, DBP, height and weight at baseline, as well as the difference between endpoint and baseline BMI z score ( $\triangle \mathrm{BMI}$ z. score) were adjusted.

All analyses were performed using Stata V.14.0, and associations were considered significant when $\mathrm{p}<0.05$.

\section{RESULTS}

According to the model fitting outcomes, a four-trajectory model with cubic specifications for all groups was 


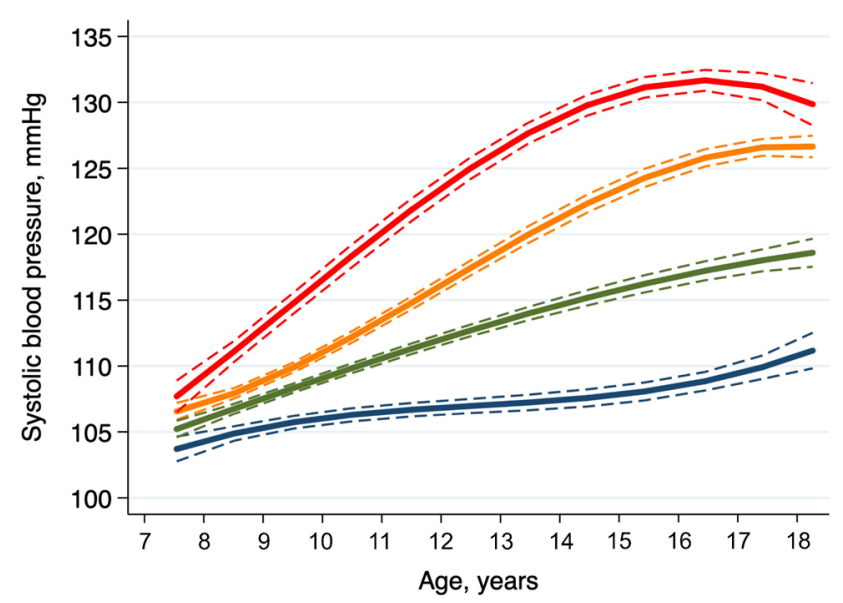

Figure 1 Plot of predicted trajectory groups systolic blood pressure trajectory groups with $95 \%$ Cls identified in Chinese boys aged $7-18$ years from a longitudinal school physical examination cohort.

identified for boys. The means and 95\% CIs of SBP were displayed in figure 1 , and the trajectories were labelled as low stable (13.0\% of participants), low rising (42.4\%), rising $(37.4 \%)$ and high rising $(7.3 \%)$. Beginning at 7 years old, the four trajectories differed significantly from each other at all ages.

The characteristics at baseline as well as those during follow-up were displayed in tables 1 and 2. Children's baseline height, weight, BMI z score, SBP and DBP were all significantly higher in those from higher SBP trajectory groups (all $\mathrm{p}$ values for trend $<0.05$ ). The average follow-up time was 8.3 (SD: 1.1) years, and the incidence rate of HBP ranged from 40.24 (95\% C: 36.68 to $44.19) / 1000$ person-years in low stable group to 97.08 (95\% CI 94.93 to 99.27 )/1000 person-years in high rising group. The difference of BMI z score remained approximately the same from baseline to the endpoint survey.

Incidence rates and 95\% CIs of HBP for each age were calculated and displayed in figure 2 by SBP trajectory group. A peak age of HBP incidence rate was discovered for each trajectory group, and that of lower SBP trajectory groups came earlier than those of higher trajectory groups. The incidence rate of HBP was constantly higher in the groups of higher SBP trajectory among all age groups, and enlarged divergence was observed with the increase of age.

The HBP risk during the follow-up, as well as HBP at endpoint, was also estimated among the four trajectory groups. Compared with low stable group, the HBP risk during the follow-up increased for 0.85 (95\% CI 0.75 to 0.96 ) to 2.98 (95\% CI 2.86 to 3.11) in crude model and for 0.85 (95\% CI 0.74 to 0.95 ) to 2.93 (95\% CI: 2.80 to 3.06 ) in adjusted model. The trend that children of higher SBP trajectory had higher risk of HBP during the follow-up was significant in both crude and adjusted models. No participants from low stable group were defined as hypertension at endpoint. Compared with low rising group, where $1.3 \%$ of the participants were hypertensive at endpoint, participants from rising group and high rising group faced 3.05 (95\% CI 2.64 to 3.46$)$ and 4.64 (95\% CI 4.18 to 5.09) times higher risk of hypertension in their late adolescence, respectively. The results did not change with adjustment of baseline age, SBP, DBP, weight, height and $\Delta$ BMI z score (table 3 ).

\section{DISCUSSION}

Using the longitudinal data from annual physical examinations with an average follow-up of 8.3 years, we identified four distinct SBP trajectories in Chinese boys aged 7-18 years. According to the results, boys of the higher SBP trajectories had greater risk of hypertension during their childhood, and had 3-4 times higher risk of becoming hypertension in their late adolescence. To our knowledge, this is one of the first studies mapping SBP trajectories in Asian children, and estimating the longterm risk of hypertension in late adolescence by different SBP trajectory groups.

In 2015, researchers from New Zealand identified four distinct BP trajectories for SBP in a longitudinal birth

Table 1 Characteristics of participants at baseline, by systolic blood pressure trajectory groups

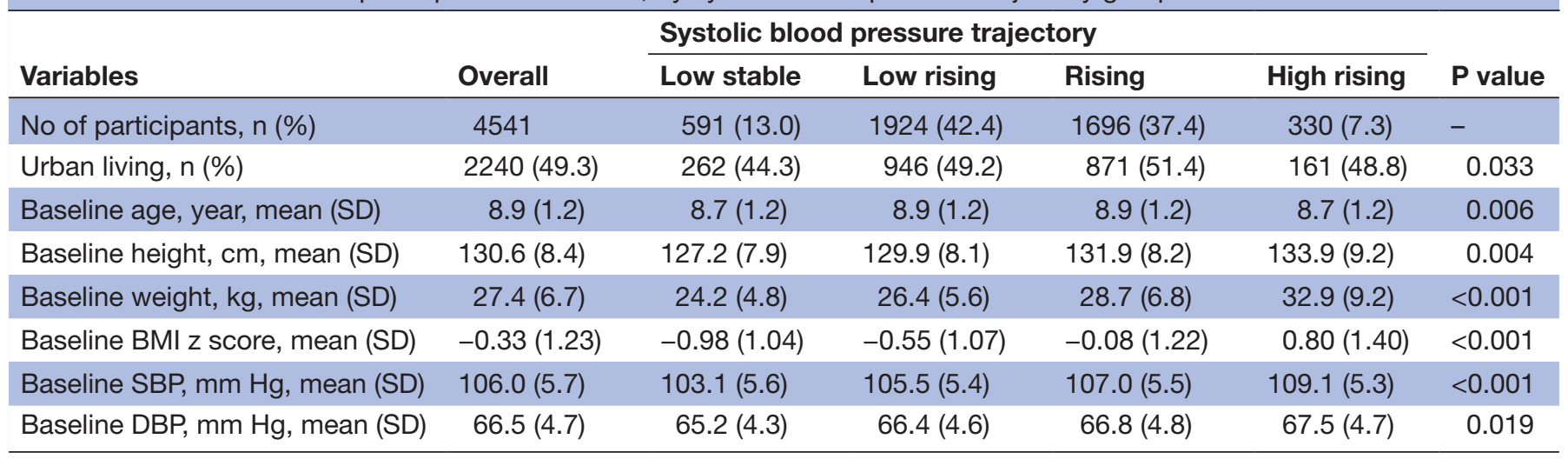

From 2006 to 2016 in Guangdong, China.

$\mathrm{BMI}$, body mass index; DBP, diastolic blood pressure; SBP, systolic blood pressure. 

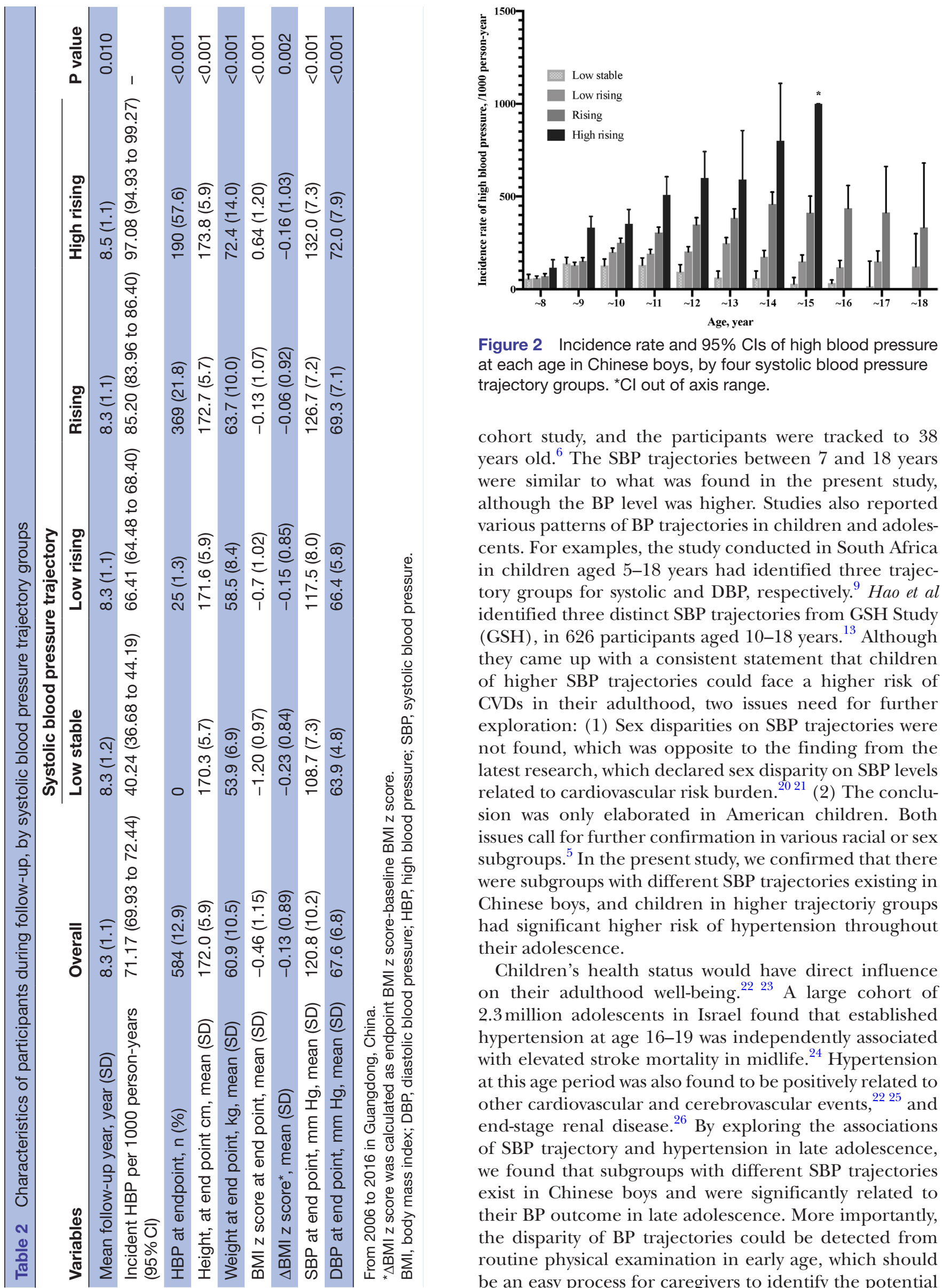

Figure 2 Incidence rate and 95\% Cls of high blood pressure at each age in Chinese boys, by four systolic blood pressure trajectory groups. ${ }^{*} \mathrm{Cl}$ out of axis range.

cohort study, and the participants were tracked to 38 years old. ${ }^{6}$ The SBP trajectories between 7 and 18 years were similar to what was found in the present study, although the BP level was higher. Studies also reported various patterns of $\mathrm{BP}$ trajectories in children and adolescents. For examples, the study conducted in South Africa in children aged 5-18 years had identified three trajectory groups for systolic and DBP, respectively. ${ }^{9} \mathrm{Hao}$ et al identified three distinct SBP trajectories from GSH Study (GSH), in 626 participants aged $10-18$ years. ${ }^{13}$ Although they came up with a consistent statement that children of higher SBP trajectories could face a higher risk of CVDs in their adulthood, two issues need for further exploration: (1) Sex disparities on SBP trajectories were not found, which was opposite to the finding from the latest research, which declared sex disparity on SBP levels related to cardiovascular risk burden. ${ }^{20}{ }^{21}$ (2) The conclusion was only elaborated in American children. Both issues call for further confirmation in various racial or sex subgroups. ${ }^{5}$ In the present study, we confirmed that there were subgroups with different SBP trajectories existing in Chinese boys, and children in higher trajectoriy groups had significant higher risk of hypertension throughout their adolescence.

Children's health status would have direct influence on their adulthood well-being. ${ }^{22}{ }^{23}$ A large cohort of 2.3 million adolescents in Israel found that established hypertension at age 16-19 was independently associated with elevated stroke mortality in midlife. ${ }^{24}$ Hypertension at this age period was also found to be positively related to other cardiovascular and cerebrovascular events, ${ }^{22}{ }^{25}$ and end-stage renal disease. ${ }^{26}$ By exploring the associations of SBP trajectory and hypertension in late adolescence, we found that subgroups with different SBP trajectories exist in Chinese boys and were significantly related to their BP outcome in late adolescence. More importantly, the disparity of $\mathrm{BP}$ trajectories could be detected from routine physical examination in early age, which should be an easy process for caregivers to identify the potential 
Table 3 Hypertensive risks of Chinese boys aged 7-18 years from different systolic blood pressure trajectory groups (coefficients and 95\% Cls)

\begin{tabular}{|c|c|c|c|c|}
\hline \multirow[b]{2}{*}{ Trajectory group } & \multicolumn{2}{|c|}{ High blood pressure during follow-up } & \multicolumn{2}{|c|}{ High blood pressure at endpoint } \\
\hline & Crude model & Adjusted model & Crude model & Adjusted model \\
\hline Low stable & 0 (Reference) & 0 (Reference) & $\mathrm{NA}^{*}$ & $N A^{*}$ \\
\hline Rising & 1.83 (1.73 to 1.93$)$ & $1.82(1.71$ to 1.92$)$ & 3.05 (2.64 to 3.46$)$ & 2.97 (2.56 to 3.39$)$ \\
\hline High rising & 2.98 (2.86 to 3.11$)$ & 2.93 (2.80 to 3.06$)$ & 4.64 (4.18 to 5.09$)$ & 4.50 (4.04 to 4.97$)$ \\
\hline
\end{tabular}

Baseline age, living area, baseline systolic and diastolic blood pressure, baseline weight and height, $\Delta \mathrm{BMI} z$ score were covariates in the adjusted model.

*There were no hypertensive participants in the group of low stable trajectory at endpoint.

BMI, body mass index; NA, not available.

risk of hypertension and provide timely interventions on reducing risk behaviours, such as increasing physical activity, maintain a healthy weight, keep a balanced diet.

Meanwhile, there was another interesting finding in present study. Between the ages of 9 and 13, a peak of HBP incidence was discovered in all trajectory groups. The peak came earlier in lower trajectory groups than in higher groups, and declined soon after, while those of rising and high rising groups remained. Previous studies have found that the increase of SBP was much greater during the puberty growth period than either before or after. ${ }^{27}$ The age of puberty growth period in Chinese boys (namely the interval between puberty onset defined by growth spurt and emission) was approximately 9.3-13.8 years old. ${ }^{28}$ Therefore, this finding suggested that the increase of HBP incidence might be related to the rapid increase of SBP during puberty growth. After the growth spurt, the SBP increase would slow down in boys in lower SBP trajectory group, while the SBP in higher trajectory groups would remain at high level, which leads to hypertension in their late adolescence. However, as pubertyrelated data, such as Tanner stage for each child, was not collected, further investigation is warranted to validate this inference.

There are limitations to be noted in the present study. First, as participants' clinical diagnosis of hypertension cannot be confirmed, the endpoint of high-risk of hypertension was defined if participants' last two measurements were deemed as HBP. Therefore, it is worthwhile to make further exploration to the relationship between SBP trajectories and diagnosed hypertension. Second, only boys were included from the original dataset. Because different models were found for girls, further research is needed to estimate their trajectories. In addition, we could only track the children to their age of 18 with the present dataset. Further study on their cardiovascular health and mortality may contribute more authority to the present topic. Third, the present study was a sencondary analysis of datasets from annual school health examinations. Risk factors of HBP development, such as lifestyle information, were unavailable.Future studies with adjusting for relevant risk behaviour information may provide further insights.

\section{CONCLUSIONS}

To conclude, the present study mapped four groups of SBP trajectories in Chinese boys aged 7-18 years old and estimated the risk of hypertension for different groups. These findings suggest that regular BP measurement could be used to identify children with elevated risk of hypertension in early age, namely at the start of puberty growth. Intervention strategies for high-risk children at or before this period could help to reduce the risk of hypertension in adolescence, as well as CVD risk in their adulthood.

Acknowledgements The authors would like to acknowledge the hard work from all the team members and the support from recruited students, teachers, parents and all the medical staff who have participated the annual physical examinations in Zhongshan, Guangdong.

Contributors $\mathrm{BD}, \mathrm{JM}$ and $\mathrm{SH}$ were coinvestigators and designer of the original study. SH and ZY helped with data collection and compliation. XW carried out the statistical analysis and drafted the manuscript. BD and JM supervised the procedure and helped revise the manuscript. JH reviewed the statistical procedure and revised the manuscript. All authors were involved in writing the manuscript and had approved the submitted version.

Funding The present research was supported by funding of National Natural Science Foundation of China (No. 81673192, rewarded to JM; No. 81903344, rewarded to BD), and Young Researcher Personal Project of Beijing to BD.

Competing interests None declared.

Patient consent for publication Not required.

Ethics approval This study has been approved for exemption of ethical application (No. IRB00001052-20011-免).

Provenance and peer review Not commissioned; externally peer reviewed.

Data availability statement Data may be obtained from a third party and are not publicly available. Extra data are available by emailing the corresponding author with reasonable justifications for the request (majunt@bjmu.edu.cn).

Supplemental material This content has been supplied by the author(s). It has not been vetted by BMJ Publishing Group Limited (BMJ) and may not have been peer-reviewed. Any opinions or recommendations discussed are solely those of the author(s) and are not endorsed by BMJ. BMJ disclaims all liability and responsibility arising from any reliance placed on the content. Where the content includes any translated material, BMJ does not warrant the accuracy and reliability of the translations (including but not limited to local regulations, clinical guidelines, 
terminology, drug names and drug dosages), and is not responsible for any error and/or omissions arising from translation and adaptation or otherwise.

Open access This is an open access article distributed in accordance with the Creative Commons Attribution Non Commercial (CC BY-NC 4.0) license, which permits others to distribute, remix, adapt, build upon this work non-commercially, and license their derivative works on different terms, provided the original work is properly cited, appropriate credit is given, any changes made indicated, and the use is non-commercial. See: http://creativecommons.org/licenses/by-nc/4.0/.

\section{ORCID iDs}

Xijie Wang http://orcid.org/0000-0002-2035-4311

Zhaogeng Yang http://orcid.org/0000-0001-9949-8360

Jun Ma http://orcid.org/0000-0003-2519-3200

\section{REFERENCES}

1 Lawes CMM, Vander Hoorn S, Rodgers A, et al. Global burden of blood-pressure-related disease, 2001. Lancet 2008;371:1513-8.

2 Mills KT, Bundy JD, Kelly TN. Global burden of hypertension: analysis of population-based studies from 89 countries. J Hypertens 2015;33.

3 Parker ED, Sinaiko AR, Kharbanda EO, et al. Change in weight status and development of hypertension. Pediatrics 2016;137:e20151662.

4 Falkner B, Gidding SS, Portman R, et al. Blood pressure variability and classification of prehypertension and hypertension in adolescence. Pediatrics 2008;122:238-42.

5 Flynn JT, Kaelber DC, Baker-Smith CM, et al. Clinical practice guideline for screening and management of high blood pressure in children and adolescents. Pediatrics 2017;140:e20171904.

6 Theodore RF, Broadbent J, Nagin D, et al. Childhood to EarlyMidlife systolic blood pressure trajectories: early-life predictors, effect modifiers, and adult cardiovascular outcomes. Hypertension 2015;66:1108-15.

7 Huxley RR, Shiell AW, Law CM. The role of size at birth and postnatal catch-up growth in determining systolic blood pressure: a systematic review of the literature. J Hypertens 2000;18:815-31.

8 Ayyavoo A, Savage T, Derraik JGB, et al. First-born children have reduced insulin sensitivity and higher daytime blood pressure compared to later-born children. J Clin Endocrinol Metab 2013;98:1248-53.

9 Kagura J, Adair LS, Munthali RJ, et al. Association between early life growth and blood pressure trajectories in black South African children. Hypertension 2016;68:1123-31.

10 Hill LK, Thayer JF. The autonomic nervous system and hypertension: ethnic differences and psychosocial factors. Curr Cardiol Rep 2019;21:15.

11 Tielemans SMAJ, Geleijnse JM, Menotti A, et al. Ten-Year blood pressure trajectories, cardiovascular mortality, and life years lost in
2 extinction cohorts: the Minnesota business and professional men study and the Zutphen study. J Am Heart Assoc 2015;4:e001378.

12 Hamer M, Kivimäki M, Batty GD. Blood pressure trajectories in youth and hypertension risk in adulthood: the 1970 British cohort study. Am $J$ Epidemiol 2020;189:162-3.

13 Hao G, Wang X, Treiber FA, et al. Blood pressure trajectories from childhood to young adulthood associated with cardiovascular risk. Hypertension 2017;69:435-42.

14 Gijón-Conde T, Sánchez-Martínez M, Graciani A, et al. Impact of the European and American guidelines on hypertension prevalence, treatment, and cardiometabolic goals. J Hypertens 2019;37:1393-400.

15 de Onis M, Onyango AW, Borghi E, et al. Development of a WHO growth reference for school-aged children and adolescents. Bull World Health Organ 2007;85:660-7.

16 Jones Bobby L, Nagin D. A Stata plugin for estimating group-based trajectory models. J Contrib 2012

17 Onis MD. WHO child growth standards based on Length/Height, weight and age. Acta Paediatr 2010;95:76-85.

18 Tu AW, Mâsse LC, Lear SA, et al. Body mass index trajectories from ages 1 to 20: results from two nationally representative Canadian longitudinal cohorts. Obesity 2015;23:1703-11.

19 Nagin DS, Jones BL, Passos VL, et al. Group-based multi-trajectory modeling. Stat Methods Med Res 2018;27:2015-23.

$20 \mathrm{Ji} \mathrm{H}$, Kim A, Ebinger JE, et al. Cardiometabolic risk-related blood pressure trajectories differ by sex. Hypertension 2020;75:1-4.

21 Sylvestre M-P, Kâ K, Dugas EN, et al. Sex-specific trajectories of systolic and diastolic blood pressure in youth. J Hypertens 2017;35:1416-23.

22 Gray L, Lee I-M, Sesso HD, et al. Blood pressure in early adulthood, hypertension in middle age, and future cardiovascular disease mortality: HAHS (Harvard alumni health study). J Am Coll Cardiol 2011;58:2396-403.

23 Sawyer SM, Afifi RA, Bearinger LH, et al. Adolescence: a foundation for future health. Lancet 2012;379:1630-40.

24 Leiba A, Twig G, Levine $\mathrm{H}$, et al. Hypertension in late adolescence and cardiovascular mortality in midlife: a cohort study of 2.3 million 16- to 19-year-old examinees. Pediatr Nephrol 2016;31:485-92.

25 Falkstedt D, Koupil I, Hemmingsson T. Blood pressure in late adolescence and early incidence of coronary heart disease and stroke in the Swedish 1969 conscription cohort. J Hypertens 2008;26:1313-20.

26 Leiba A, Fishman B, Twig G, et al. Association of adolescent hypertension with future end-stage renal disease. JAMA Intern Med 2019;179:517-23.

27 Shankar RR, Eckert GJ, Saha C, et al. The change in blood pressure during pubertal growth. J Clin Endocrinol Metab 2005;90:163-7.

28 Liang Y, Mi J. Pubertal hypertension is a strong predictor for the risk of adult hypertension. Biomed Environ Sci 2011;24:459-66. 